\title{
Impact of Varying Exercise Intensity on Oxygen Uptake and Cardiovascular Response during Body Weight Supported Treadmill Walking in Healthy Adults
}

\author{
R. Scott Van Zant ${ }^{1}$, Wick R. Colchagoff ${ }^{2}$, Josh Addis ${ }^{2}$, Joel Daloz ${ }^{2}$, Maureen Gill², Jenna \\ Moskow $^{2}$ and Aubrey Norris ${ }^{2}$
}

${ }^{1}$ Doctor of Physical Therapy Program, Hanover College, USA

${ }^{2}$ Physical Therapy Program, University of Findlay, USA

*Corresponding author: $R$ Scott Van Zant PT, PhD, Doctor of Physical Therapy Program, Hanover College, 517 Ball Drive, Hanover, IN 47243, USA, Tel: 412-491-2723

\begin{abstract}
Background: Body Weight Supported Treadmill Training (BWSTT) is effectively used in locomotive training for patients with neurologic and musculoskeletal deficits. The impact of BWSTT on oxygen uptake $\left(\mathrm{VO}_{2}\right)$ and cardiovascular (HR and $\mathrm{BP}$ ) response in patients has been shown to be variable, possibly due to level of Body Weight Support (BWS) or exercise intensity. The purpose of this study was to compare and quantify $\mathrm{VO}_{2}, \mathrm{HR}$, and $\mathrm{BP}$ response in healthy adults during BWSTT at $0 \%$ and $30 \%$ BWS for two exercise intensities (35\% and $50 \% \mathrm{VO}_{2} \max$ ).

Methods: Eleven subjects ( 6 female, 5 male; $41.9 \pm 11.3 \mathrm{y}$; $177.3 \pm 6.9 \mathrm{~cm} ; 79.0 \pm 17.5 \mathrm{~kg} ; 24.9 \pm 4.2 \mathrm{~kg} / \mathrm{m}^{2}$ ) provided informed consent for participation. Each completed a 5-minute rest trial followed by four treadmill walking trials; 2 at $35 \% \mathrm{VO}_{2} \max (0 \%$ and $30 \%$ BWS; trials 0035 and 3035$)$ and 2 at $50 \% \mathrm{VO}_{2} \max (0 \%$ and $30 \%$ BWS; trials 0050 and 3050). Subjects rested a minimum of 5 minutes between each trail. For each trial the following was measured: HR (electronic monitor), BP (auscultation), RPE (Borg ratio scale), $\mathrm{VO}_{2}$ (indirect calorimetry). Mean data from minutes 3-5 were analyzed for differences between levels of BWS and exercise intensity levels using repeated measures ANOVA and Bonferroni post-hoc testing.
\end{abstract}

Results: Mean walking speeds and elevations were 86.7 $\mathrm{m} / \mathrm{min}$ and $0.6 \%\left(35 \% \mathrm{VO}_{2} \max \right)$ and $91.1 \mathrm{~m} / \mathrm{min}$ and $3.7 \%$ $\left(50 \% \mathrm{VO}_{2}\right.$ max). All trials showed significant $(p<0.05)$ increases in HR, RPE, VO, metabolic equivalents (MET), minute ventilation (VE), Respiratory Rate (RR) and tidal volume (TV) compared to rest. No significant differences were seen in any tested variables between 0035 and 3035 .
$\mathrm{HR}, \mathrm{VO}_{2}, \mathrm{METS}$, and VE were significantly decreased in 3050 vs. 0050 . HR, RPE, $\mathrm{VO}_{2}, \mathrm{METS}$, respiratory exchange ratio and TV were significantly reduced in 0035 and 3035 compared to 0050 but were not different compared to 3050 .

Conclusion: BWS of $30 \%$ did not induce significant changes in $\mathrm{VO}_{2} \mathrm{HR}$ or $\mathrm{BP}$ response while walking at $35 \%$ $\mathrm{VO}_{2}$ max but did show significant reductions in $\mathrm{HR}$ and $\mathrm{VO}_{2}$ walking at $50 \% \mathrm{VO}_{2}$ max. Further, $30 \%$ BWS while walking at $50 \% \mathrm{VO}_{2}$ max elicited similar $\mathrm{VO}_{2}$ and $\mathrm{HR}$ responses to unweighted walking at $35 \% \mathrm{VO}_{2}$ max. This suggests $\mathrm{BWS}$ may allow for higher intensity exercise in patients while yielding reduced patient responses in $\mathrm{VO}_{2}$ and $\mathrm{HR}$.

\section{Keywords}

Body weight supported gait, Cardiorespiratory response, Exercise intensity

\section{Introduction}

Gait training has shown to be an effective and functional intervention to include in populations with neurologic and musculoskeletal impairments as a method to help prevent cardiorespiratory and physical decline [1-3]. However, many patients that have dysfunction in these areas often present barriers to effective means of performing gait training in the clinical setting. Recently, body weight supported treadmill training (BWSTT) has become a popular method to provide safe and effective intervention to these patient populations [4-11]. 
Body weight supported treadmill training commonly involves a mechanical lift or harness system over a treadmill that works to unload a calculated percentage of body weight while also providing upright stabilization and support for the individual. Benefits of unloading body weight during ambulation in the clinical setting include improved patient and clinician safety, increased clinician capabilities for hands-on treatment during ambulation, decreased ground reaction forces that allow for reduced musculoskeletal pain $[5,12,13]$, improved walking distance and step length in persons with Parkinson disease $[7,8]$, improved walking speed and endurance [6], enhanced physiological wellbeing [14], and allowing for repetitive, task-specific gait training required for optimal neuroplastic motor learning [1]. Additionally, early and regular BWSTT has been demonstrated to have positive effects on the prevention and treatment of muscle atrophy, normal glucose tolerance, insulin sensitivity, and regulation of autonomic nervous system after spinal cord injury $(\mathrm{SCl})$ [3].

Despite the abundance of consistent positive findings in use of BWSTT treating musculoskeletal and neurological conditions, there is conflicting evidence regarding the metabolic and cardiorespiratory response of BWSTT in both healthy and impaired adult populations. Several previous studies [15-18] have demonstrated decreased oxygen uptake $\left(\mathrm{VO}_{2}\right)$ with unloading body weight during walking or running trials in healthy adults. In particular, Farley and McMahon [15] noted that the degree of reduction in $\mathrm{VO}_{2}$ with BWSTT seemed proportional to exercise intensity. For example, they noted that while running at $75 \%$ BWS, $\mathrm{VO}_{2}$ reduction was $71 \%$, but walking at that same level of $\mathrm{BWS}$ resulted in only a $33 \%$ reduction in $\mathrm{VO}_{2}$.

In contrast to the above investigations, several studies $[13,14,19]$ have found no change in $\mathrm{VO}_{2}$ with BWSTT. Hoffman and Donaghe [13] showed through linear regression analysis similar response to $\mathrm{VO}_{2}$ and HR in 12 healthy subjects walking at $25 \%$ and $50 \%$ BWS. MacKay-Lyons, et al. [14] studied 15 adults over the age of 40 without neurological impairments during BWSTT in varying conditions. These included treadmill training without BWS device, as well as BWSTT with $0 \%$, and $15 \%$ BWS during progressive exercise with a $2.5 \%$ grade incline increment every 2 minutes at a constant speed until volitional fatigue. Results indicated no significant difference in $\mathrm{VO}_{2}$ among the subject trials. Van Zant, et al. [19] studied healthy adults aged 18-50 walking at a self-selected speed (approximating 36-40\% age normative $\mathrm{VO}_{2}$ max) with $\mathrm{BWS}$ at $0,15 \%, 30 \%$, and found no significant changes in $\mathrm{VO}_{2}$ or cardiovascular ( $\mathrm{HR}$ and $\mathrm{BP}$ ) responses.

It has been noted that aging may impact the relationship of BWS and metabolic demand. Van Zant, et al. [20] found that in comparing BWSTT at 0,
$15 \%, 30 \%$ in healthy older adults (age $50-80$ years), a significant reduction in $\mathrm{VO}_{2}$ was seen at $30 \% \mathrm{BWS}$, but no changes were noted in HR or BP. Subjects walked at a self-selected speed that approximated $44-48 \%$ of their age normative $\mathrm{VO}_{2}$ max. Musolf, et al. [21] found similar responses indicating weight support reduced $\mathrm{VO}_{2}$ to a greater extent in elderly populations compared to younger subjects. A systematic review by Das Gupta, et al. [22] analyzed the metabolic energy of walking in healthy young adults compared to healthy older adults and found consistent evidence showing a significant increase in metabolic energy demand for the elderly population [23].

It would seem that several factors, including degree of BWS, exercise intensity, and aging, may impact the metabolic and cardiovascular response of BWSTT. The purpose of this study is to compare and quantify metabolic $\left(\mathrm{VO}_{2}\right)$ and cardiovascular ( $\mathrm{HR}$ and $\mathrm{BP}$ ) effects in healthy adults of a broad age range (ages 18-75) during BWSTT at $0 \%$ and $30 \%$ under varying exercise intensities ( $30 \%$ and $50 \%$ of predicted $\mathrm{VO}_{2}$ max). We hypothesize that there will be a decrease in $\mathrm{VO}_{2}, \mathrm{HR}$, and systolic $\mathrm{BP}$ with increasing BWS percentagesand exercise intensity that will indicate an ability to perform functional mobility at a lesser metabolic and cardiovascular demand during supported treadmill walking. This research could lead to solidifying the foundation in understanding the effects of BWSTT in a diverse age population for better application to a broad population under varying BWSTT conditions.

\section{Methods}

\section{Subjects}

Prior to subject recruitment, the study design and test protocol were approved by the institutional research review board of the University of Findlay, Findlay, Ohio (project \#1367). A total of 11 subjects ( 6 female, 5 male) volunteered to participate in the study and provided their informed consent. Subjects were recruited as a sample of convenience via email or flyer recognition within the community and among the faculty and staff of the research institution. Inclusion criteria of the study was limited to apparently healthy individuals within the age range of 18 and 75 years. Exclusion criteria of the study included any lower extremity injury that resulted in limitation to recreational or vocational participation for more than one day within the previous six months, or diagnosed cardiovascular disease, diabetes, cancer, pulmonary disease that would impact normal metabolic or cardiovascular response to moderate level exercise. Table 1 summarizes the subject characteristics. The original test protocol called for testing 20 subjects to match similar work done by this laboratory $[19,20]$, however the impact of the COVID-19 pandemic limited data collection to the defined 11 subjects. A power test [23] using previous study $\mathrm{VO}_{2}$ data indicated that 10 subjects would be necessary to identify a true difference 
of $4 \%$, with a $5 \%$ probability of a Type I error and a $20 \%$ probability of a Type II error.

Prior to laboratory testing, each participant completed the Rockport Walking Test [24] to predict $\mathrm{VO}_{2}$ max. Subjects walked 1 mile on a measured course, and upon immediate conclusion of the walk, HR was measured via palpation by a research team member. Time to complete the walk, HR at end of the walk, and subject age, body weight, and sex were used in the prediction equation to determine $\mathrm{VO}_{2}$ max. From this predicted value, $\mathrm{VO}_{2}$ levels of $35 \%$ and $50 \% \mathrm{VO}_{2}$ max were calculated, and treadmill speed (maximum of 91.1 $\mathrm{m} / \mathrm{min}$ ) and grade values were calculated for subsequent laboratory testing [25]. These exercise intensities were selected to approximate self-selected speeds of subjects from previous investigations at this laboratory $[19,20]$.

\section{Measures and procedures}

Each subject was assigned an identification number. Subjects were randomly assigned (by coin flip) to a testing order for pre-determined walking speed (35\% or $50 \% \mathrm{VO}_{2} \max$ ) and level of BWS (0\% or $\left.30 \%\right)$. A total for 4 walking trials (designated as 0035, 3035, 0050, 3050 for their BWS and intensity levels) were completed, and all subjects were blind to both walking speed and level of BWS. Subject height and weight were recorded using a standard beam scale and stadiometer with shoes removed. Subjects were fitted with a wireless $\mathrm{HR}$ monitor (Polar Beat, Polar, Bethpage, NY) for HR assessment throughout the testing. The subject was then fitted for a body weight support harness. The harness was applied in supine in order to achieve proper alignment. Upon standing, the subject was assessed for any further harness adjustments needed to ensure participant

Table 1: Subject Characteristics ( $N=11,6$ Female, 5 male).

\begin{tabular}{|l|l|l|}
\hline Factors & Mean \pm SD & Range \\
\hline Age $(\mathrm{yr})$ & $41.91 \pm 11.28$ & $22-61$ \\
\hline Height $(\mathrm{cm})$ & $177.28 \pm 6.96$ & $167.60-191.00$ \\
\hline Weight $(\mathrm{kg})$ & $79.04 \pm 17.51$ & $57.20-107.90$ \\
\hline $\mathrm{BMl}\left(\mathrm{kg} / \mathrm{m}^{2}\right)$ & $24.93 \pm 4.18$ & $19.30-32.20$ \\
\hline $\mathrm{VO}_{2} \max (\mathrm{mL} / \mathrm{kg} / \mathrm{min})^{\star}$ & $37.50 \pm 4.65$ & $30.70-45.90$ \\
\hline
\end{tabular}

${ }^{*}$ Predicted via 1-mile walk per Kline, et al. [24] comfort and proper harness position. Seated resting HR, BP (via standard auscultation), and Borg Rating of Perceived Exertion (RPE) ratio scale were documented. The testing protocol was explained to participants at this time. The participant was then fitted with a oneway breathing valve (Hans Rudolph, Inc., Kansas City, MO) for collection of expired air that was analyzed via indirect calorimetry. Due to the impact of COVID-19 on the data collection schedule, two different gas analysis systems were used. For 7 subjects the Trumax 2400 Metabolic Measurement System, Parvo Medics, Sandy, UT was used, while for the remaining 4 subjects an iWorx MC-Peak Metabolic Cart, Dover, NH was used. For both systems, all tests were calibrated for volume using a 3-liter calibration syringe, and for gas composition using authenticated calibration gas. Seated resting assessment for five minutes was then conducted with $\mathrm{HR}, \mathrm{BP}$, and RPE assessed each minute, and metabolic data $\left[\mathrm{VO}_{2}\right.$, Respiratory Rate (RR), Tidal Volume (TV), Respiratory Exchange Ratio (RER), Metabolic Equivalents (MET)] measured continuously.

Following resting assessment, the subject stood on the center of the treadmill belt and was connected to the unweighting system (Biodex Offset Unweighing System, Biodex, Shirley, NY). After the desired level of BWS was achieved, the subject straddled the treadmill belt, the predetermined speed set, and the first of four 5-minute exercise trials commenced. Data collection for each exercise trial mirrored that of the resting trial previously described. At the conclusion of the exercise trial, the subject was removed from the breathing valve, and sat quietly for at least 5 minutes prior to starting the next trial. Subject HR was constantly monitored during this rest period to ensure it was $\leq 5 \mathrm{bpm}$ of their resting HR before commencing the next exercise trial. Mean data derived from minutes 3,4 , and 5 for the resting and each exercise trial for $\mathrm{VO}_{2}$ RR, TV, RER, MET, HR, SBP, DBP, and RPE was analyzed for differences regarding both walking speed and level of BWS via repeated measures analysis of variance (ANOVA) using SPSS Version 25 (IBM, New York, NY). Statistically significant differences between trials were identified using Bonferroni post-hoc testing.

\section{Results}

The overall mean treadmill speed and grade for $35 \%$

Table 2: Cardiovascular and RPE Responses.

\begin{tabular}{|l|l|l|l|l|l|}
\hline Factor & Rest & $\mathbf{0 0 3 5}$ & $\mathbf{3 0 3 5}$ & $\mathbf{0 0 5 0}$ & $\mathbf{3 0 5 0}$ \\
\hline HR $(\mathrm{bpm})$ & $71.0 \pm 9.9$ & $102.3 \pm 10.3^{\mathrm{a}, \mathrm{c}}$ & $103.5 \pm 12.9^{\mathrm{a}, \mathrm{d}}$ & $113.3 \pm 11.1^{\mathrm{a}, \mathrm{b}, \mathrm{c}, \mathrm{d}}$ & $106.3 \pm 11.0^{\mathrm{a}, \mathrm{b}}$ \\
\hline SBP $(\mathrm{mmHg})$ & $123.5 \pm 9.3$ & $133.2 \pm 8.9$ & $131.9 \pm 10.7$ & $135.1 \pm 11.0$ & $134.0 \pm 11.0$ \\
\hline DBP $(\mathrm{mmHg})$ & $76.9 \pm 9.4$ & $78.0 \pm 8.5$ & $77.4 \pm 6.8$ & $76.9 \pm 7.9$ & $77.6 \pm 7.1$ \\
\hline RPE & $1.7 \pm 0.5$ & $2.5 \pm 0.6^{\mathrm{a}, \mathrm{c}}$ & $2.6 \pm 0.5^{\mathrm{a}, \mathrm{d}}$ & $3.3 \pm 0.7^{\mathrm{a}, \mathrm{c}, \mathrm{d}}$ & $3.1 \pm 0.9^{\mathrm{a}}$ \\
\hline
\end{tabular}

KEY: HR: Heart Rate; SBP: Systolic Blood Pressure; DBP: Diastolic Blood Pressure; RPE: Rating of Perceived Exertion (Borg Ratio Scale); $0035=0 \% \mathrm{BWS} / 35 \% \mathrm{VO}_{2} \max ; 3035=30 \% \mathrm{BWS} / 35 \% \mathrm{VO}_{2} \max ; 0050=0 \% \mathrm{BWS} / 50 \% \mathrm{VO} \mathrm{O}_{2} \max ; 3050=30 \%$ $\mathrm{BWS} / 50 \% \mathrm{VO}_{2} \max$

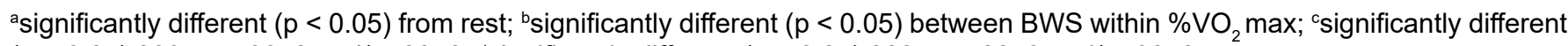
$(p<0.05) 0035$ vs. 0050 and/or 3050; dsignificantly different $(p<0.05) 3035$ vs. 0050 and/or 3050 
$\mathrm{VO}_{2}$ max trials was 86.7 meters $/ \mathrm{min}$ and $0.6 \%$, and for the $50 \% \mathrm{VO}_{2}$ max trials was 91.1 meters $/ \mathrm{min}$ and $3.7 \%$. Table 2 summarizes the cardiovascular (HR and BP) and RPE responses at rest and for each of the walking trials. All walking trials demonstrated significant $(p<0.05)$ increases in HR and RPE from rest, but no significant changes were seen in SBP or DBP. Heart rate and RPE were significantly different between the $35 \% \mathrm{VO}_{2}$ trials (0035 and 3035) and trial 0050, but not trial 3050. Body weight support applied at $35 \% \mathrm{VO}_{2}$ max showed no difference in $\mathrm{HR}$ or RPE response, but $\mathrm{HR}$ was significantly reduced between trials 0050 and 3050 .

Table 3 summarizes the $\mathrm{VO}_{2}$ and ventilatory responses among rest and the walking trials. With the exception of RER, all variables were significantly elevated from rest. With the exception of RR, all studied variables were significantly increased between the $35 \% \mathrm{VO}_{2}$ trials and trial 0050. RER was significantly different between trial 0035 and 3050, and VE was significantly different between trial 3035 and 3050 . Body weight support at $35 \% \mathrm{VO}_{2}$ max showed no difference among measured variables, while $\mathrm{VO}_{2}, \mathrm{MET}$ and $\mathrm{VE}$ were significantly decreased in trial 3050 compared to trial 0050.

\section{Discussion}

The purpose of this study was to compare and quantify $\mathrm{VO}_{2}$ and cardiovascular (HR, BP) effects in healthy adults of ages 18-75 during BWSTT at $0 \%$ and $30 \%$ BWS under varying exercise intensities $(35 \%$ and $50 \%$ of predicted $\mathrm{VO}_{2}$ max). We found that at $35 \% \mathrm{VO}_{2}$ max, BWSTT up to $30 \%$ BWS did not significantly impact $\mathrm{VO}_{2}$ and $\mathrm{HR}$ response. Interestingly, the exercising at $50 \% \mathrm{VO}_{2}$ max during $30 \%$ BWS was found to reduce the subject's $\mathrm{VO}_{2}$ and $\mathrm{HR}$ response. This suggests that the impact of BWSTT on $\mathrm{VO}_{2}$ and $\mathrm{HR}$ response is influenced by exercise intensity, thus supporting the study hypothesis. These results are supported by prior research by Van Zant, et al. [20] who found that healthy older adults (50-74 years-old), exercising at self-selected speeds comparable to $44-48 \%$ of $\mathrm{VO}_{2}$ max, did show reduced $\mathrm{VO}_{2}$ metabolic rates at $30 \% \mathrm{BWS}$. In contrast, these results differ from the findings of Grabowski, et al.
[16] who also described decreased metabolic demand during walkingat a constant speed of 2.8 miles per hour $(75.0 \mathrm{~m} / \mathrm{min})$, but level of BWS was considerably greater (50\% and $75 \%$ )in these trials. Importantly, the ages of the subjects in this study are unknown and therefore, exercise intensity as a percentage of $\mathrm{VO}_{2}$ max cannot be hypothesized. This data suggests that BWS may allow for higher intensity exercise in an expansive group of patient populations that may be otherwise limited by large fluctuations in $\mathrm{VO}_{2}$ and $\mathrm{HR}$ responses.

Similar to work of Lefeber, et al. [26] the effects of BWS yielded noted differences in $\mathrm{VO}_{2}$ and cardiorespiratory demand. These authors found that in ambulatory stroke survivors, metabolic markers of exertion during robot assisted gait were less than over ground walking when in BWS walking [26]. However, during BWS minimum thresholds of exercise demand were reached, and therefore complement our findings that BWS exercise can reach intensities sufficient to challenge the cardiopulmonary system to promote gainful adaptation. In a 2018 study Foley, et al. [27] quantified and compared metabolic responses during treadmill running under increasing loads of BWS. They highlighted that $\mathrm{VO}_{2^{\prime}}$ VE, TV, HR, and oxygen pulse significantly decreased with increasing BWS while running at intensities corresponding the subject's anaerobic threshold. This research is consistent not only with our results, but also those of Farley and McMahon [15], demonstrating that reduction of metabolic variables with BWS are exercise intensity dependent.

A limitation to this research study was a decrease in the participant pool for subjects to test due to COVID-19 restrictions which impacted the availability of older subjects and decreased the patient population representation. External validity may be compromised due to the small sample size used. The harness system used for our study to provide BWS was difficult to fit snugly to a variety of subjects with different anthropometrics. Some of the subjects found the apparatus uncomfortable and restrictive. A possibility for BP alteration was also present from the increased intra-abdominal pressures associated with the abdominal binder portion of the

Table 3: Oxygen Uptake and Ventilatory Responses.

\begin{tabular}{|l|l|l|l|l|l|}
\hline Factor & Rest & $\mathbf{0 0 3 5}$ & $\mathbf{3 0 3 5}$ & $\mathbf{0 0 5 0}$ & 3050 \\
\hline $\mathrm{VO}_{2}(\mathrm{~mL} / \mathrm{kg} / \mathrm{min})$ & $3.6 \pm 0.7$ & $15.5 \pm 2.4^{\mathrm{a}, \mathrm{c}}$ & $14.4 \pm 2.7^{\mathrm{a}, \mathrm{d}}$ & $19.3 \pm 2.9^{\mathrm{a}, \mathrm{b}, \mathrm{c}, \mathrm{d}}$ & $15.5 \pm 2.0^{\mathrm{a}, \mathrm{b}}$ \\
\hline $\mathrm{MET}$ & $1.0 \pm 0.2$ & $4.4 \pm 0.7^{\mathrm{a}, \mathrm{c}}$ & $4.1 \pm 0.8^{\mathrm{a}, \mathrm{d}}$ & $5.5 \pm 0.8^{\mathrm{a}, \mathrm{b}, \mathrm{c}, \mathrm{d}}$ & $4.4^{\mathrm{a}} \pm 0.6^{\mathrm{a}, \mathrm{b}}$ \\
\hline $\mathrm{VE}(\mathrm{L} / \mathrm{min})$ & $7.9 \pm 1.8$ & $23.4 \pm 6.0^{\mathrm{a}, \mathrm{c}}$ & $22.9 \pm 5.9^{\mathrm{a}, \mathrm{d}}$ & $29.7 \pm 8.1^{\mathrm{a}, \mathrm{b}, \mathrm{c}, \mathrm{d}}$ & $25.9 \pm 6.4^{\mathrm{a}, \mathrm{b}, \mathrm{d}}$ \\
\hline RER & $0.86 \pm 0.09$ & $0.81 \pm 0.04^{\mathrm{c}}$ & $0.82 \pm 0.03^{\mathrm{d}}$ & $0.87 \pm 0.04^{\mathrm{c}, \mathrm{d}}$ & $0.86 \pm 0.04^{\mathrm{c}}$ \\
\hline RR (br/min) & $17.2 \pm 3.8$ & $22.5 \pm 5.9^{\mathrm{a}}$ & $25.1 \pm 6.2^{\mathrm{a}}$ & $24.1 \pm 6.0^{\mathrm{a}}$ & $26.7 \pm 5.2^{\mathrm{a}}$ \\
\hline TV (L) & $0.57 \pm 0.21$ & $1.34 \pm 0.66^{\mathrm{a}, \mathrm{c}}$ & $1.10 \pm 0.33^{\mathrm{a}, \mathrm{d}}$ & $1.55 \pm 0.69^{\mathrm{a}, \mathrm{c}, \mathrm{d}}$ & $1.13 \pm 0.22^{\mathrm{a}}$ \\
\hline
\end{tabular}

KEY: VO : oxygen uptake; MET: Metabolic Equivalents; VE: Minute Ventilation; RER: Respiratory Exchange Ratio; RR: Respiratory Rate; TV: Tidal Volume; $0035=0 \% \mathrm{BWS} / 35 \% \mathrm{VO}_{2} \max ; 3035=30 \% \mathrm{BWS} / 35 \% \mathrm{VO}_{2} \max ; 0050=0 \% \mathrm{BWS} / 50 \% \mathrm{VO}$ max; 3050 $=30 \% \mathrm{BWS} / 50 \% \mathrm{VO}_{2} \max$

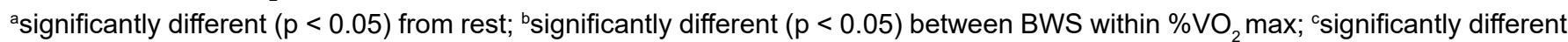
$(p<0.05) 0035$ vs. 0050 and/or 3050; 'significantly different $(p<0.05) 3035$ vs. 0050 and/or 3050 
harness. The harness compression on chest expansion may have had an impact on the TV of participants when active on the treadmill during the $30 \%$ BWS exercise bouts, which may have subsequently influenced RR in the tested subjects. Further investigation is warranted in other BWS support systems that aren't as restrictive of the abdominal and thoracic cavities during exercise such as the use of an Alter-G BWS treadmill.

In order for clinicians to appropriately develop exercise prescriptions, there is a need to understand the expected metabolic changes that occur during a specific level of exercise. While working with complex patient populations, such as those who are cardiopulmonary compromised, have motor control deficits, or musculoskeletal conditions, it is accurate to assume that treadmill training has safety limitations. However, BWSTT has the potential to safely exercise these patients while achieving the beneficial physiological adaptations of aerobic exercise. The results of this study demonstrated that the use of BWS can allow for exercising subjects at higher absolute exercise intensities without inducing the $\mathrm{VO}_{2}$ and $\mathrm{HR}$ responses typical of exercising at the higher intensities. The reduction of stress placed on the cardiopulmonary and cardiovascular systems indicates the potential to exercise complex patients at higher intensities to improve their aerobic capacity safely. In addition, those who do not tolerate full weight bearing exercises are able to benefit from the use of BWS to exercise at parameters at a higher intensity to improve aerobic capacity. However, further research is warranted among the mentioned complex patient populations to investigate the impact that BWS training can have on their cardiopulmonary and cardiovascular function. Future reproduction and confirmation of these results would be important clinically, as it would work to support exercising patients at higher intensities using BWSTT while realizing reduced metabolic demands.

\section{Conclusion}

In conclusion, the results of this study suggest that in healthy adult subjects the effect of reducing $\mathrm{VO}_{2}$ and $\mathrm{HR}$ with walking BWSTT is influenced by exercise intensity, and that BWS levels of $30 \%$ allow for performing higher intensity exercise without significantly increased $\mathrm{VO}_{2}$ and $\mathrm{HR}$ response.

\section{Acknowledgement}

The authors wish to thank the subjects who gave generously of their time to participate in this study during the difficult challenges posed by the COVID-19 pandemic.

\section{Competing Interests}

The authors declare that they have no competing interests.

\section{Funding}

No external funding supported this research.

\section{Statement of Author Contribution}

All authors contributed to data collection and analysis, manuscript composition and review, and agreed with the order of presentation of authors. RSV and WRC were responsible for original study development.

\section{References}

1. MacKay-Lyons M, McDonald A, Matheson J, Eskes G, Klus MA (2013) Dual effects of body-weight supported treadmill training on cardiovascular fitness and walking ability early after stroke: A randomized controlled trial. Neurorehab Neuro Rep 27: 644-653.

2. Billinger SA, Coughenour E, Mackay-Lyons MJ, Ivey FM (2012) Reduced cardiorespiratory fitness after stroke: biological consequences and exercise-induced adaptations. Stroke Res Treat 2012: 959120.

3. Hicks AL, Ginis KM (2008) Treadmill training after spinal cord injury: it's not just about the walking. J Rehabil Res Dev 45: 241-248.

4. Apte S, Plooij M, Vallery H (2018) Influence of body weight unloading on human gait characteristics: a systematic review. J NeuroEngineering Rehabil 15.

5. Peeler J, Christian M, Cooper J, Leiter J, Mac Donald P (2015) Managing knee osteoarthritis: The effects of body weight supported physical activity on joint pain, function, and thigh muscle strength. Clin J Sport Med 25: 518-523.

6. Mehrholz J, Thomas S, Elsner B (2017) Treadmill training and body weight support for walking after stroke. Cochrane Database Syst Rev 8: CD002840.

7. Miyai I, Fujimoto $Y$, Yamamoto $H$, Ueda $Y$, Saito $T$, et al. (2002) Long-term effect of body weight-supported treadmill training in Parkinson's disease: A randomized controlled trial. Arch Phys Med Rehabil 83: 1370-1373.

8. Atan T, Özyemişci Taşkıran Ö, Bora Tokçaer A, Kaymak Karataş G, Karakuş Çalışkan A, et al. (2019) Effects of different percentages of body weight-supported treadmill training in Parkinson's disease: A double-blind randomized controlled trial. Turk J Med Sci 49: 999-1007.

9. Rome ET, Deitrick RW, Drapeau L, Kelly JM, Heffernan K (2001) Cardiorespiratory and metabolic effects of varying degrees of unweighted treadmill walking. Med Sci Sports Exerc 33: S22.

10. Mansour WT, Atya AM, Ahmed M (2013) Improving Gait and Balance in Multiple Sclerosis Using Partial Body Weight Supported Treadmill Training. Egypt J Neurol Psychiatry Neurosurg 50: 271-276.

11. Aaslund MK, Helbostad JL, Moe-Nilssen R (2013) Walking during body-weight-supported treadmill training and acute responses to varying walking speed and body-weight support in ambulatory patients post-stroke. Physiother Theory Pract 29: 278-289.

12. Ogston J (2017) Unweighting Effects in a Novel Unweighted Treadmill System during Walking and Running. Clin Kinesiol (Online Edition). Fall 34-39.

13. Hoffman MD, Donaghe HE (2011) Physiological Responses to Body Weight-Supported Treadmill Exercise in Healthy Adults. Arch Phys Med Rehabil 92: 960-966.

14. MacKay-Lyons M, Makrides L, Speth S (2001) Effect of $15 \%$ body weight support on exercise capacity of adults without impairments. Phys Ther 81: 1790-1800. 
15. Farley CT, McMahon TA (1992) Energetics of walking and running: Insights from simulated reduced-gravity experiments. J Appl Physiol 73: 2709-2712.

16. Grabowski A, Farley CT, Kram R (2005) Independent metabolic costs of supporting body weight and accelerating body mass during walking. J Appl Physiol 98: 579-583.

17. Teunissen LP, Grabowski A, Kram R (2007) Effects of independently altering body weight and body mass on the metabolic cost of running. J Exp Biol 210: 4418-4427.

18. Danielsson A, Sunnerhagen KS (2000) Oxygen consumption during treadmill walking with and without body weight support in patients with hemiparesis after stroke and in healthy subjects. Arch Phys Med Rehabil 81: 953-957.

19. Van Zant RS, Colchagoff W, Kunish M, et al. (2020) Metabolic and cardiovascular effects of body weight support treadmill walking in healthy adults. Cardiopulm Phys Ther $\mathrm{J}$ 31: 167-171.

20. Van Zant RS, Colchagoff W, Cox A, et al. (2019) Metabolic and cardiovascular effects of body weight support treadmil walking in healthy older adults. Med Sci Sport Exerc 51: S882.

21. Musolf SA, Ortega JD (2020) The effects of aging on the metabolic cost of supporting body weight during walking.
22. Das Gupta S, Bobbert MF, Kistemaker DA (2019) The metabolic cost of walking in healthy young and older adults - A systematic review and meta-analysis. Sci Rep 9: 1-10.

23. Steel RGD, Torrie JH (1980) Principles and Procedures of Statistics. ( $2^{\text {nd }}$ edn), New York: McGraw-Hill.

24. Kline G, Porcari JP, Hintermeister R, Freedson PS, Ward A, et al. (1987) Estimation of VO2max from a one-mile track walk, gender, age, and body weight. Med Sci Sports Exerc 19: 253-259.

25. Riebe D, Ehrman JK, Liguori G, Magal M (2018) ACSMs Guidelines for Exercise Testing and Prescription. (10 ${ }^{\text {th }}$ edn), Philadelphia: Wolters Kluwer.

26. Lefeber N, De Keersmaecker E, Henderix S, Michielsen M, Kerckhofs E, et al. (2018) Physiological Responses and Perceived Exertion During Robot-Assisted and Body Weight-Supported Gait After Stroke. Neurorehabil Neural Repair 32: 1043-1054.

27. Foley M, Bean D, Jernigan D (2018) Quantification and comparison of metabolic and cardiorespiratory responses to increasing levels of support during bodyweight-supported treadmill running in trained runners running at anaerobic threshold. J Exerc Physiol Online 21: 1-11. 